\title{
Impact of Aestheticians' Perception of Alternative Medicine on the Management Performance
}

\author{
Won-Bum Shin ${ }^{1}$, Young-Sam Kim ${ }^{2 *}$ \\ ${ }^{1}$ Department of Cosmetics Engineering, Konkuk University, Seoul, Korea \\ ${ }^{2}$ Department of Imaging Industry, Graduate School of Engineering, Konkuk University, Seoul, Korea
}

\author{
"Corresponding author: Young-Sam Kim, \\ Department of Imaging Industry, Graduate \\ School of Engineering, Konkuk University, \\ 120 Neungdong-ro, Gwangjin-gu, Seoul \\ 05029, Korea \\ Tel.: +82 24500463 \\ Email: gracehelen@konkuk.ac.kr
}

Received June 30, 2020

Revised August 12, 2020

Accepted August 25, 2020

Published September 30, 2020

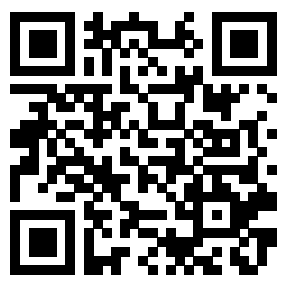

\begin{abstract}
Purpose: This is a quantitative study in which the impact of perception of alternative medicine on management performance was investigated and analyzed using participants in a skin care retraining program for the purpose of meeting customer needs. Methods: An online survey was administered among 596 men and women across the country, who are currently working on skin care, from February 1 to February 20, 2020. The collected data were analyzed using SPSS WIN 25.0. One-way ANOVA, $t$-test, $x^{2}$ test, and frequency analysis were conducted to verify awareness and perception of alternative medicine, experience, attitude and reliability of alternative medicine treatment, status and perception of alternative medicine training, and perceptions of usefulness of alternative medicine. In addition, multiple regression analyses were conducted to find out the factors that affect the satisfaction of using alternative medicine and its usefulness. Results: When estheticians were asked how effective it was to provide alternative medicine to customers, after receiving the training on alternative medicine, $32.2 \%$ of the respondents said that it contributed to the increase in profit by $50 \%$, whereas $27.9 \%$ said that it contributed to the increase in the number of customers by $20 \%-30 \%$. The results show that the more positive attitudes, the higher reliability toward the alternative medicine, and the stronger perceived needs toward the opening of alternative medicine, the higher level of satisfaction by its users. Conclusion: Therefore, it seems that retraining programs on alternative medicine, as well as changes in the system, are needed.
\end{abstract}

Keywords: Aesthetician, Alternative medicine, Perception, Retraining, Management performance

\section{Introduction}

현대인의 평균수명이 늘어나고 경제 성장 및 과학과 의학의 발 달은 노령화를 가져왔으며, 건강과 건강관리요법에 대한 관심이 매 우 높아지고 있다. 현대 사회가 발전하는 동시에 이에 따른 부작용 으로 환경오염이 증가하고 이에 따라 알레르기성 비염, 피부병, 천 식 등 환경과 관련된 질환, 과도한 영양 섭취로 인한 심혈관계질환, 당뇨, 비만 등의 대사증후군, 스트레스로 인한 소화기, 정신과 질 환 및 각종 성인병이 증가하고 있다. 또한 의학의 발달과 경제수준 의 향상으로 노령 인구 및 만성 질환의 증가로 인한 삶의 질의 향상 에 대한 요구가 높아지고 있다. 그 뿐만 아니라 의료수요의 다양화
로 인하여 질병의 치료뿐만 아니라 건강의 유지 증진 목적으로 대 체의학에 대한 의료인과 일반인의 관심 또한 증가하고 있는 추세 이다(Lee et al., 2010). 인간 생명의 존엄성과 고귀함은 의학의 발 달을 가져왔고(Kim, 2001), 특히 만성 질환자들이 대체 의학을 통 해 증상 완화, 삶의 질 향상 그리고 질병치유 등의 다양한 효과를 기 대하며(Daykin \& Richardson, 2004) 연령이 증가할수록 대체의학 및 대체요법을 더 많이 경험하고 있고(Choi et al., 2009), 이용 종 류 수 또한 연령이 영향을 미치고(Park \& Hyun, 2011) 있다. 대체 의학(alternative medicine)은 현대의학 혹은 대증의학을 제외한 모 든 종류의 전통의학, 민간 요법으로서 환경에너지, 생체에너지, 천 연치료제등을 이용하여 인체의 항상성(homeostasis)을 도와 원래 
의 건 강한 신체로 회복하도록 하는데 그 목적을 두고 있다(Han et al., 2012). 이와 같은 사회 분위기 속에 의료와 미용을 접목한 융합 형 인재 양성이 요구되고(Kim, 2019), 급변하는 환경과 기업들간 의 치열한 경쟁 속에서 미용서비스업은 다른 산업에 비해 인적자원 의 의존도가 높은 서비스업(Kim \& Lee, 2018)으로 미용서비스업의 종사자는 전문적인 분야로 지식과 기술, 정보의 증가에 맞춰 고객 에게 만족을 주는 업무를 수행(Min et al., 2013)하게 된다. 이와 같 은 사회 분위기 속에 의료와 미용을 접목한 융합형 인재 양성이 요 구되고 피부 관리 분야에서도 대체의학을 접목하여 전문성을 강조 하고(Rhee, 2016)있는 추세이다. 피부 관리가 미적인 부분에서뿐만 아니라 정신, 신체, 환경 등 전체적인 균형적 조화를 지향하며(Kim, 2009), 전인적인 피부 관리를 하려는 경향으로 인해 대체의학에 관 심을 갖고 이를 발전시켜 나가려 한다. 피부 관리와 관련된 대체의 학으로는 마사지, 근막이완법, 두개천골요법, 아유르베다, 림프마사 지, 발반사요법, 등이 있고, 신체적, 감성적 웰빙을 추구하는 전인적 트리트먼트(Kang \& Jang, 2012)로 신체뿐만 아니라 정신적, 심리 적으로도 영향을 미치며 우울, 불안, 스트레스, 피로, 근육이완, 수면 촉진, 면역증강 등에 매우 탁월한 효과가 있는(Jeon \& Woo, 2014) 것으로 알려진 아로마요법도 포함된다. 대체의학적 기법을 선호하는 사람들일수록 대체의학에 대한 인지도가 높게 나타나며(Yoo et al., 1999), 피부 관리실에서 활용되는 대체의학의 종류도 날로 늘어 피 부 관리뿐만 아니라 건강관리 방법으로 대체의학이 활용되고 있다.

이러한 대체의학은 피부 관리실에서 고객들의 질 높은 서비스에 대한 요구를 만족시키기 위해서, 높은 경쟁우위 전략 중 하나가 될 수 있다. 경쟁우위를 갖기 위해 대부분의 피부 관리실에서는 대체의 학을 이용하여 피부 관리뿐만이 아니라 측만증 같은 체형관리, 비만 관리, 스트레스관리, 위장 장애나 변비 같은 장기 관리, 만성통증 관 리 등 질병의 예방과 관리에 도움을 주고 있다. 피부 관리실에서 재 교육 필요성을 강하게 느끼고 있고(Jeong \& Choi, 2008), 대체의학 의 활용도와 중요성이 증가하기 때문에, 피부관리사들은 고객의 니 즈(needs)를 충족시키기 위해서 대체의학에 대한 재교육을 받고 있 다(Rhee, 2016).

피부관리사의 재교육은 현재 미용관련 대학이나 학원, 제품 회사, 협회 및 학회, 직장상사 및 동료 등을 통하여 활발히 이루어지고 있 다(Jung et al, . 2014). 그러나 피부관리실에서 대체의학을 이용하는 데 체계적이고 학문적인 정립이 제대로 되어있지 않고 피부 관리사 들의 대체의학의 인식과 활용에 있어 과학적인 입증이 제대로 되어 있지 않은 것이 문제점으로 지적된다. 그리고 재교육 프로그램이 피 부관리사들의 교육에 대한 열의에 비해 비체계적이고 비 표준화 되 어있기 때문에 전문적인 교육이 부족하다고 인식하고 있다. 또한 재 교육에 투자되는 비용이 높아 피부관리사들에게 경제적인 부담을 갖 게 하고, 바쁜 업무 시간으로 인해 자유롭게 재교육을 받을 수 없다 는 문제도 발생 한다(Jung et al,. 2014).

대체의학이 독립적 제도적 장치가 미흡한 상황에서 의료영역으로
간주되기 쉬운 까닭에 피부 관리 범주에 포함하고자 하는 것은 많은 제약이 따르며 이러한 상황에서 피부관리사들에게 대체의학 범주의 적용의 효율성이 제고될 필요성이 있다.

따라서 본 연구는 재교육 프로그램 참여 피부관리사 대상으로 대 체의학 재교육이 경영성과에 미치는 영향을 연구하고자 한다.

\section{Methods}

\section{1. 연구 대상 및 자료 수집}

본 연구는 피부미용 재교육 프로그램을 수강하고 있는 전국의 피 부 관리사 성인 남성 178 명, 여성 418 명을 대상으로 2020 년 2월 1일 부터 2 월 20 일까지 설문을 실시하여 대체의학에 대한 인식도를 조사 하고, 이를 바탕으로 대체의학 인식도와 재교육이 경영성과에 미치 는 영향을 살펴보는 데에 목적이 있다. 온라인 설문을 통하여 연구의 목적에 대하여 설명한 후 동의를 구한 자에 한해 설문을 실시하였다. 피부관리사들의 연령, 성별, 피부 관리실 근무기간과 대체의학 이 용경험, 교육경험에 따른 대체의학의 이용 만족도, 수익 증대, 고객 증가에 미치는 영향에 대하여 연구 한다.

\section{2. 자료 분석}

본 연구의 수집된 자료 596부는 Statistical Package for the Social Science (SPSS) WIN 25.0 프로그램을 이용하여 분석하였 다. 분석기법으로는 연구대상자의 일반적 특성을 파악하기 위해 빈 도와 백분율을 산출하였다. 또한 피부관리사들의 대체의학 인지도 및 인식, 대체의학 요법에 대한 경험 및 태도, 신뢰도, 대체의학의 교 육 실태 및 인식, 대체의학 요법의 유용성에 대한 인식을 알아보기 위해 one-way ANOVA (일원변량분석)과 $t$-test (검증), $\chi^{2}$ (Chisquare) 검증, 그리고 빈도분석을 실시하였다. 또한 대체의학 이용 만족도와 유용성에 영향을 미치는 요인을 알아보기 위해 multiple regression (다중회귀분석)을 실시하였다

\section{Results and Discussion}

\section{1. 연구대상자의 특성}

본 연구의 연구대상자의 일반적 특성은 Table 1 과 같다.

총 596 명 중 연령별로는 50 대가 $51.3 \%$ 로 절반 이상을 차지하였 으며, 다음으로 40 대 $32.7 \%, 60$ 대 이상 $10.6 \%, 30$ 대 $4.9 \%, 20$ 대 $0.5 \%$ 순으로 나타났다. 성별로는 여성이 $70.1 \%$ 로 남성 $29.9 \%$ 보 다 높은 분포를 보였다. 피부 관리실 근무기간별로는 10년 이상이 $36.2 \%$ 로 가장 많았으며, 다음으로 1년 미만 23.3\%, 5-10년 미만 $15.9 \%, 1-3$ 년 미만 $12.4 \%, 3-5$ 년 미만 $12.2 \%$ 순으로 나타났다. 


\section{2. 측정도구의 신뢰성 분석}

본 연구 측정도구의 신뢰도를 검증한 결과는 Table 2 과 같다. Table 2에서 보는 바와 같이 Cronbach $\alpha$ 가 대체의학 이용 만족도 0.69 , 대체의학에 대한 태도 0.74 , 대체의학에 대한 신뢰도 0.68 로, 모두 0.60 이상으로 나타났다. 따라서 본 연구의 측정도구는 신뢰할 만한 수준임을 알 수 있다.

\section{2. 대체의학 재교육 후 경영성과에 미치는 영향}

1) 대체의학 학습 후 고객 적용 시 샵의 수익에 도움이 된 정도

$\mathrm{A}$ 업체에서 대체의학 학습 후 고객 적용 시 샵의 수익에 도움이 된 정도에 대해 피부관리사들의 인식을 살펴본 결과는 Table 3 와 같 이 A 업체에서 대체의학 학습 후 고객 적용 시 샵의 수익에 $50 \%$ 이 상 도움이 되었다고 인식하는 피부관리사가 $32.2 \%$ 로 가장 많았으 며, 다음으로 20-30\%가 $21.8 \%, 30-40 \%$ 가 $19.5 \%, 10-20 \%$ 가 $19.0 \%, 0 \%$ 가 $7.6 \%$ 순으로 나타났다. 이는 Kim (2009)의 연구에서 대체의학이 피부 관리실 매출에 긍정적인 역할을 하고 있다고 인식 한 비율이 $50 \%$ 이상이며, 피부관리실 근무하는 미용인들의 $97 \%$ 가 대체의학의 적용 필요성에 공감한다는 결과와 일치한다.

연령별로는 40대 이하인 피부관리사가 그렇지 않은 피부관리사보 다 A 업체에서 대체의학 학습 후 고객 적용 시 샵의 수익에 $50 \%$ 이상 도움이 되었다고 인식하는 비율이 높았고, 50 대 이상인 피부관리사 와 60 대 이상인 피부관리사 모두 $50 \%$ 이상 도움이 되었다고 인식하 였으나 통계적으로는 유의미한 차이를 보이지 않았다. 성별로는 남 성 피부관리사가 여성 피부관리사보다 $\mathrm{A}$ 업체에서 대체의학 학습 후 고객 적용 시 샵의 수익에 $50 \%$ 이상 도움이 되었다고 인식하였고, 여 성 피부관리사도 남성 피부관리사보다 50\%이상 도움이 되었다고 인
식하였으나 유의미한 차이는 아니었다.

피부 관리실 근무기간별로는 1-3년 미만인 피부관리사는 A 업체 에서 대체의학 학습 후 고객 적용 시 샵의 수익에 30-40\% 도움이 되었다고 인식하였고, 3-10년 미만인 피부관리사는 $50 \%$ 이상 도움 이 되었다고 인식하였다. 그리고 10 년 이상인 피부관리사도 $50 \%$ 이 상 도움이 되었다고 인식하였고, 피부 관리실 근무기간에 따라 유의 미한 차이를 보였다 $\left(\chi^{2}=29.98, p<0.05\right)$. 대체의학 이용 경험 별로 는 대체의학을 이용한 적이 있는 피부관리사는 고객 적용 시 샵의 수 익에 $50 \%$ 이상 도움이 되었다고 인식하였고, 대체의학을 이용한 적 이 없는 피부관리사는 10-20\% 도움이 되었다고 인식하였으나 대체 의학 이용경험에 따른 유의미한 차이는 없었다. 대체의학 교육 경험 별로는 대체의학에 대해 교육을 받은 적이 있는 피부관리사는 $\mathrm{A}$ 업 체에서 대체의학 학습 후 고객 적용 시 샵의 수익에 $50 \%$ 이상 도움 이 되었다고 인식하였고, 대체의학에 대해 교육을 받은 적이 없는 피 부관리사는 10-20\% 도움이 되었다고 인식하였으며, 대체의학 교육 경험에 따라 유의미한 차이를 보였다 $\left(\chi^{2}=35.07, p<0.001\right)$.

이상과 같이 피부관리사들은 A 업체에서 대체의학 학습 후 고객 적용 시 샵의 수익에 도움이 많이 되었다고 인식하는 것으로 사료된 다.

2) 대체의학 재교육 후 고객 적용 시 고객 수 증가에 도움이 된 정도 $\mathrm{A}$ 업체에서 대체의학 학습 후 고객 적용 시 고객 수 증가에 도움 이 된 정도에 대해 피부관리사들의 인식을 살펴본 결과는 Table 4 와 같이 A 업체에서 대체의학 학습 후 고객 적용 시 고객 수 증가에 20-30\% 도움이 되었다고 인식하는 피부관리사가 27.9\%로 가장 많 았으며, 다음으로 10-20\%가 $24.0 \%, 50 \%$ 이상이 $21.1 \%, 30-40 \%$

Table 1. General characteristics of the study subjects

\begin{tabular}{|c|c|c|c|}
\hline Division & & Frequency $(\mathrm{N})$ & Percentage (\%) \\
\hline \multirow{5}{*}{ Age (years) } & $20 s$ & 3 & 0.5 \\
\hline & $30 \mathrm{~s}$ & 29 & 4.9 \\
\hline & $40 \mathrm{~s}$ & 195 & 32.7 \\
\hline & $50 s$ & 306 & 51.3 \\
\hline & Over 60s & 63 & 10.6 \\
\hline \multirow{2}{*}{ Sex } & Male & 178 & 29.9 \\
\hline & Female & 418 & 70.1 \\
\hline \multirow{5}{*}{$\begin{array}{l}\text { Number of years } \\
\text { working in skin care }\end{array}$} & $<1$ & 139 & 23.3 \\
\hline & $1-3$ & 74 & 12.4 \\
\hline & $3-5$ years & 73 & 12.2 \\
\hline & $5-10$ years & 95 & 15.9 \\
\hline & $>10$ & 215 & 36.2 \\
\hline Total & & 596 & 0 \\
\hline
\end{tabular}

Table 2. Reliability of measurement tools

\begin{tabular}{lcc}
\hline Division & No. of items & Cronbach's $\alpha$ \\
Satisfaction of using alternative medicine & 3 & 0.69 \\
Attitude on alternative medicine & 6 & 0.74 \\
Reliability on alternative medicine & 5 & 0.68 \\
\hline
\end{tabular}


가 $19.5 \%, 0 \%$ 가 $7.6 \%$ 순으로 나타났다.

연령별로는 40 대 이하인 피부관리사가 그렇지 않은 피부관리사보 다 A 업체에서 대체의학 학습 후 고객 적용 시 고객 수 증가에 20$30 \%$ 도움이 되었다고 인식하였고, 50 대는 $50 \%$ 이상, 60 대 이상은 20-30\% 도움이 되었다고 인식하였으나, 연령별 유의미한 차이는 나타나지 않았다. 성별로는 남성과 여성 피부관리사 모두 A 업체에 서 대체의학 학습 후 고객 적용 시 고객 수 증가에 20-30\% 도움이 되었다고 인식한 비율이 높았으나, 성별에 따른 유의미한 차이는 없 었다. 피부 관리실 근무기간별로는 $\mathrm{A}$ 업체에서 대체의학 학습 후 고 객 적용 시 고객 수 증가에 1 년 미만인 피부관리사는 20-30\%, 1-3
년 미만인 피부관리사는 10-20\%, 3-5년 미만인 피부관리사는 50\% 이상, 5-10년 미만인 피부관리사는 20-30\%, 10년 이상인 피부관 리사는 20-30\% 도움이 되었다고 인식하였으나 통계적으로는 유의 미한 차이를 보이지 않았다.

대체의학 이용 경험 별로는 대체의학을 이용한 적이 있는 피부관 리사는 $\mathrm{A}$ 업체에서 대체의학 학습 후 고객 적용 시 고객 수 증가에 20-30\% 이상 도움이 되었다고 인식하였고, 대체의학을 이용한 적 이 없는 피부관리사는 10-20\% 도움이 되었다고 인식하였으나 유의 미한 차이는 아니었다. 대체의학 교육 경험 별로는 대체의학에 대해 교육을 받은 적이 있는 피부관리사는 A 업체에서 대체의학 학습 후

Table 3. The degree to which alternative medicine contributed to profit when it was provided to customers after receiving training on alternative medicine

\begin{tabular}{|c|c|c|c|c|c|c|c|c|c|}
\hline Division & & $0 \%$ & $10-20 \%$ & $20-30 \%$ & $30-40 \%$ & over $50 \%$ & Total & $x^{2}(d f)$ & $p$ \\
\hline \multirow{3}{*}{ Age (years) } & $\leq 40$ s & $17(7.5)$ & 36 (15.9) & $52(22.9)$ & $53(23.3)$ & $69(30.4)$ & 227 (38.1) & \multirow{3}{*}{$10.60(8)$} & \multirow{3}{*}{0.225} \\
\hline & $50 s$ & $22(7.2)$ & $70(22.9)$ & $62(20.3)$ & $50(16.3)$ & $102(33.3)$ & 306 (51.3) & & \\
\hline & $\geq 60 \mathrm{~s}$ & $6(9.5)$ & 7 (11.1) & $16(25.4)$ & $13(20.6)$ & 21 (33.3) & $63(10.60)$ & & \\
\hline \multirow{2}{*}{ Sex } & M & $14(7.9)$ & 33 (18.5) & 33 (18.5) & $41(23.0)$ & $57(32.0)$ & 178 (29.9) & \multirow[t]{2}{*}{$2.97(4)$} & \multirow[t]{2}{*}{0.563} \\
\hline & $\mathrm{F}$ & $31(7.4)$ & 80 (19.1) & $97(23.2)$ & 75 (17.9) & 135 (32.3) & 418 (70.1) & & \\
\hline \multirow{5}{*}{$\begin{array}{l}\text { Number of years } \\
\text { working in skin } \\
\text { care }\end{array}$} & $<1$ & 18 (12.9) & $28(20.1)$ & $25(18.0)$ & $34(24.5)$ & $34(24.5)$ & $139(23.3)$ & \multirow[t]{5}{*}{$29.98^{*}(16)$} & \multirow[t]{5}{*}{0.018} \\
\hline & $1-3$ & $2(2.7)$ & 16 (21.6) & $15(20.3)$ & $21(28.4)$ & $20(27.0)$ & $74(12.4)$ & & \\
\hline & $3-5$ & $5(6.8)$ & $15(20.5)$ & 11 (15.1) & $14(19.2)$ & $28(38.4)$ & 73 (122.0) & & \\
\hline & $5-10$ & $6(6.3)$ & 15 (15.8) & $19(20.0)$ & $18(18.9)$ & 37 (38.9) & 95 (15.9) & & \\
\hline & $>10$ & $14(6.5)$ & 39 (18.1) & 60 (27.9) & $29(13.5)$ & $73(34.0)$ & 215 (36.2) & & \\
\hline \multirow{5}{*}{$\begin{array}{l}\text { Experience of } \\
\text { using alternative } \\
\text { medicine } \\
\text { Experience of receiving } \\
\text { alternative medicine } \\
\text { training } \\
\text { Total }\end{array}$} & Yes & $36(6.9)$ & $92(17.7)$ & $117(22.5)$ & $103(19.8)$ & $173(33.2)$ & $521(87.4)$ & \multirow[t]{2}{*}{$8.20(4)$} & \multirow[t]{2}{*}{0.085} \\
\hline & No & $9(12.0)$ & $21(28.0)$ & $13(17.3)$ & $13(17.3)$ & 19 (25.3) & 75 (12.6) & & \\
\hline & Yes & $31(5.8)$ & $95(17.7)$ & $118(22.0)$ & $108(20.1)$ & $184(34.3)$ & $536(89.9)$ & $35.07^{* * *}(4)$ & 0.000 \\
\hline & No & $14(23.3)$ & $18(30.0)$ & $12(20.0)$ & $8(13.3)$ & $8(13.3)$ & 60 (10.1) & & \\
\hline & & $45(7.6)$ & $113(19.0)$ & $130(21.8)$ & $116(19.5)$ & $192(32.2)$ & $596(100.0)$ & & \\
\hline
\end{tabular}

Table 4. The degree to which alternative medicine contributed to an increase in the number of customers when it was provided to customers after receiving training on alternative medicine

\begin{tabular}{|c|c|c|c|c|c|c|c|c|c|}
\hline Division & & $0 \%$ & $10-20 \%$ & $20-30 \%$ & $30-40 \%$ & over $50 \%$ & Total & $x^{2}(d f)$ & $p$ \\
\hline \multirow{3}{*}{ Age (years) } & $\leq 40 s$ & $17(7.5)$ & 52 (22.9) & 61 (26.9) & $56(24.7)$ & 41 (18.1) & 227 (38.1) & \multirow{3}{*}{$14.06(8)$} & \multirow{3}{*}{0.080} \\
\hline & $50 s$ & $21(6.9)$ & 83 (27.1) & 83 (27.1) & 49 (16.0) & 70 (22.9) & 306 (51.3) & & \\
\hline & $\geq 60 s$ & 7 (11.1) & $8(12.7)$ & 22 (34.9) & 11 (17.5) & $15(23.8)$ & $63(10.60)$ & & \\
\hline \multirow{2}{*}{ Sex } & $\mathrm{M}$ & $16(9.0)$ & 35 (19.7) & 45 (25.3) & 39 (21.9) & $43(24.2)$ & 178 (29.9) & \multirow{2}{*}{$5.16(4)$} & \multirow{2}{*}{0.272} \\
\hline & $\mathrm{F}$ & $29(6.9)$ & $108(25.8)$ & $121(28.9)$ & 77 (18.4) & 83 (19.9) & 418 (70.1) & & \\
\hline \multirow{5}{*}{$\begin{array}{l}\text { Number of years } \\
\text { working in skin care }\end{array}$} & $<1$ & $15(10.8)$ & 29 (20.9) & 43 (30.9) & 28 (20.1) & $24(17.3)$ & 139 (23.3) & \multirow{5}{*}{$19.30(16)$} & \multirow{5}{*}{0.253} \\
\hline & $1-3$ & $3(4.1)$ & $22(29.7)$ & 15 (20.3) & 21 (28.4) & 13 (17.6) & 74 (12.4) & & \\
\hline & $3-5$ & $5(6.8)$ & $18(24.7)$ & 14 (19.2) & $16(21.9)$ & $20(27.4)$ & 73 (122.) & & \\
\hline & $5-10$ & $6(6.3)$ & 20 (21.1) & $28(29.5)$ & $20(21.1)$ & 21 (22.1) & 95 (15.9) & & \\
\hline & $>10$ & $16(7.4)$ & 54 (25.1) & $66(30.7)$ & 31 (14.4) & $48(22.3)$ & 215 (36.2) & & \\
\hline \multirow{2}{*}{$\begin{array}{l}\text { Experience of using } \\
\text { alternative medicine }\end{array}$} & Yes & $35(6.7)$ & $121(23.2)$ & 149 (28.6) & $101(19.4)$ & 115 (22.1) & $521(87.4)$ & \multirow{2}{*}{$7.36(4)$} & \multirow{2}{*}{0.118} \\
\hline & No & $10(13.3)$ & $22(29.3)$ & $17(22.7)$ & $15(20.0)$ & $11(14.7)$ & $75(12.6)$ & & \\
\hline \multirow{2}{*}{$\begin{array}{l}\text { Experience of receiving } \\
\text { alternative medicine } \\
\text { training }\end{array}$} & Yes & $31(5.8)$ & 123 (22.9) & $154(28.7)$ & 108 (20.1) & $120(22.4)$ & 536 (89.9) & \multirow[b]{2}{*}{$31.12^{* * *}(4)$} & \multirow[b]{2}{*}{0.000} \\
\hline & No & $14(23.3)$ & $20(33.3)$ & $12(20.0)$ & $8(13.3)$ & $6(10.0)$ & 60 (10.1) & & \\
\hline Total & & $45(7.6)$ & $143(24.0)$ & $166(27.9)$ & $116(19.5)$ & $126(21.1)$ & 596 (100.0) & & \\
\hline
\end{tabular}


고객 적용 시 고객 수 증가에 20-30\% 이상 도움이 되었다고 인식 하였고, 대체의학에 대해 교육을 받은 적이 없는 피부관리사는 10$20 \%$ 도움이 되었다고 인식하였으며, 대체의학 교육경험에 따라 유 의미한 차이를 보였다 $\left(\chi^{2}=31.12, p<0.001\right)$.

이상과 같이 대체의학에 대해 교육을 받은 적이 있는 피부관리사 가 그렇지 않은 피부관리사보다 대체의학 학습 후 고객 적용 시 고객 수 증가에 도움이 많이 되었다고 인식하는 것으로 해석된다.

\section{3. 대체의학 재교육 후 경영성과에 미치는 영향 요인 분석}

1) 대체의학 재교육 후 고객 적용 시 샵의 수익 증가 영향요인

$\mathrm{A}$ 업체에서 대체의학 학습 후 고객 적용 시 샵의 수익 증가에 도 움이 된 정도에 영향을 미치는 요인에 대해 살펴본 결과는 Table 5 와 같다. 대체의학 학습 후 고객 적용 시 샵의 수익 증가에 도움이 된 정도에 영향을 미치는 요인을 살펴보면, 이 프로그램은 적합성이 검
증되었으며 $(F=10.656, p<0.001)$ 약 $14.1 \%\left(\mathrm{R}^{2}=0.141\right)$ 의 설명력 을 지니고 있다. 피부관리사들의 $\mathrm{A}$ 업체에서 대체의학 학습 후 고 객 적용 시 샵의 수익 증가에는 대체의학 인지도 $(\beta=0.127, p<0.01)$ 과 대체의학에 대한 신뢰도 $(\beta=0.115, p<0.05)$, 대체의학 교육경험 $(\beta=0.166, p<0.01)$, 대체의학 교육 필요성( $\beta=0.112, p<0.05)$, 그리 고 대체의학 정규과목 개설 필요 $(\beta=0.120, p<0.01)$ 이 통계적으로 유 의미한 정(+)의 영향을 미쳤다.

$\mathrm{A}$ 업체에서 대체의학 학습 후 대체의학에 대한 경험이 있고, 신뢰 도가 높아 대체의학에 대한 이해도가 높을수록, 대체의학의 고객 적 용 시 샵의 수익 증가에 도움이 되었다고 인식하는 것으로 해석된다.

2) 대체의학 재교육 후 고객 적용 시 고객 수 증가 영향요인

$\mathrm{A}$ 업체에서 대체의학 학습 후 고객 적용 시 고객 수 증가에 도움 이 된 정도에 영향을 미치는 요인에 대해 살펴본 결과는 Table 6 과

Table 5. The degree to which alternative medicine contributed to an increase in profit when it was provided to customers after receiving training on alternative medicine

\begin{tabular}{|c|c|c|c|c|}
\hline \multirow{2}{*}{ Division } & \multicolumn{4}{|c|}{ Profit increase } \\
\hline & $b$ & $\beta$ & $t$ & $p$ \\
\hline Perception of alternative medicine & 0.197 & 0.127 & $2.702^{* *}$ & 0.007 \\
\hline Experience of using alternative medicine (yes $=1$ ) & -0.183 & -0.051 & -1.046 & 0.296 \\
\hline Attitude on alternative medicine & 0.120 & 0.058 & 1.171 & 0.242 \\
\hline Reliability on alternative medicine & 0.278 & 0.115 & $2.318^{*}$ & 0.021 \\
\hline Experience of alternative medicine training (yes $=1$ ) & 0.699 & 0.166 & $3.477^{* *}$ & 0.001 \\
\hline Necessity of training on alternative medicine & 0.199 & 0.112 & $2.397^{*}$ & 0.017 \\
\hline Necessity of opening a regular course of alternative medicine (yes=1) & 0.574 & 0.120 & $2.676^{* \star}$ & 0.008 \\
\hline Constant & & & $2.671^{* *}$ & 0.008 \\
\hline $\mathrm{R}^{2}$ & \multicolumn{4}{|c|}{0.141} \\
\hline$F(p)$ & \multicolumn{4}{|c|}{$10.656^{* * *}(0.000)$} \\
\hline
\end{tabular}

${ }^{*} p<0.05 ;{ }^{* *} p<0.01 ;{ }^{* * *} p<0.001$.

Table 6. The degree to which alternative medicine contributed to an increase in the number of customers when it was provided to customers after receiving training on alternative medicine

\begin{tabular}{|c|c|c|c|c|}
\hline \multirow{2}{*}{ Division } & \multicolumn{4}{|c|}{ Increase in the number of customers } \\
\hline & $\mathrm{b}$ & $\beta$ & $t$ & $p$ \\
\hline Perception of alternative medicine & 0.160 & 0.111 & $2.328^{*}$ & 0.020 \\
\hline Experience of using alternative medicine (yes $=1$ ) & -0.149 & -0.044 & -0.903 & 0.367 \\
\hline Attitude on alternative medicine & 0.157 & 0.081 & 1.619 & 0.106 \\
\hline Reliability on alternative medicine & 0.321 & 0.142 & $2.843^{* *}$ & 0.005 \\
\hline Experience of alternative medicine training (yes=1) & 0.532 & 0.135 & $2.811^{* *}$ & 0.005 \\
\hline Necessity of training on alternative medicine & 0.126 & 0.076 & 1.610 & 0.108 \\
\hline Necessity of opening a regular course of alternative medicine (yes=1) & 0.494 & 0.111 & $2.443^{*}$ & 0.015 \\
\hline Constant & & & $2.704^{* *}$ & 0.007 \\
\hline $\mathrm{R}^{2}$ & \multicolumn{4}{|c|}{0.126} \\
\hline$F(p)$ & \multicolumn{4}{|c|}{$9.369^{* * *}(0.000)$} \\
\hline
\end{tabular}

${ }^{*} p<0.05 ;{ }^{* *} p<0.01 ;{ }^{* * *} p<0.001$. 
같다. A 업체에서 대체의학 학습 후 고객 적용 시 고객 수 증가에 도 움이 된 정도에 영향을 미치는 요인을 살펴보면, 이 프로그램은 적합 성이 검증되었으며( $F=9.369, p<0.001)$, 약 $12.6 \%\left(\mathrm{R}^{2}=0.126\right)$ 의 설 명력을 지니고 있다. 피부관리사들의 $\mathrm{A}$ 업체에서 대체의학 학습 후 고객 적용 시 고객 수 증가에는 대체의학 인지도 $(\beta=0.111, p<0.05)$ 과 대체의학에 대한 신뢰도 $(\beta=0.142, p<0.01)$, 대체의학 교육경험 $(\beta=0.135, p<0.01)$, 그리고 대체의학 정규과목 개설 필요 $(\beta=0.111$, $p<0.05)$ 이 통계적으로 유의미한 정 $(+)$ 의 영향을 미쳤다.

이상과 같이, 피부관리사들은 A 업체에서 대체의학 학습 후 대체 의학에 대한 신뢰도와 이해도가 높아져 대체의학 적용 시 고객 증가 에 도움이 되었다고 인식하는 것으로 해석된다.

\section{Conclusion}

본 연구는 피부 관리사의 대체의학재교육이 미용경영성과에 미치 는 영향에 대해서 검증하였으며 연구결과는 다음과 같다.

첫째, 대체의학 재교육이 미용 경영성과에 미치는 영향에 대해서 알아 본 결과, 대체의학 학습 후 고객 적용 시 $32.2 \%$ 의 피부관리사 가 샵의 수익에 $50 \%$ 이상 도움이 되었다고 한 것이 가장 많이 조사되 었고, 다음으로는 30-40\%이상은 $19.5 \%, 20-30 \%$ 는 $21.8 \%, 10-$ $20 \%$ 는 $19.0 \%, 0 \%$ 도 $7.6 \%$ 가 조사되었다

샵의 고객 수 증가에 대한 조사를 보면 대체의학 학습 후 고객 적 용이 20-30\% 고객 수가 증가되었다는 응답이 27.9\%로 가장 많았 고, $10-20 \%$ 가 $24.0 \%, 50 \%$ 이상이 $21.1 \%, 30-40 \%$ 가 $19.5 \%, 0 \%$ 는 $7.6 \%$ 로 조사되었다.

둘째, 대체의학 재교육이 미용 경영성과 영향 요인을 분석 결과, 대체의학에 대한 태도가 긍정적일수록, 대체의학에 대한 신뢰도가 높을수록, 그리고 대체의학 정규 과목 개설이 필요하다고 인식할수 록 대체의학 이용 만족도가 높음을 알 수 있다. 대체의학 재교육 후 고객 적용 시 샵의 수익과 고객 증가에 도움이 되는 것으로 조사되었 다.

본 연구를 통해서 대체의학 재교육 후 고객 적용 시 수익 증가와 고객 증가에 도움이 되었다고 인식했다. 따라서 대체의학에 대한 인 식도를 높이고, 수익과 고객 수 증가에 도움이 되기 위해서 대체의학 에 대한 재교육이 필요하다고 사료된다. 피부관리사의 재교육은 해 당 분야에서 요구되는 지식과 기술을 향상시켜 고객에게 제공하는 서비스의 효과를 높일 수 있고, 조직이 환경변화에 능동적으로 대처 하고, 안정성이 확보되며, 직원의 직무 만족도 향상으로 인한 고객 만족도도 향상되어 경영성과에 영향을 줄 수 있다. 그리고 피부관리 사들이 활용하고 있는 대체의학이 독립적인 한 분야로써 인정받기 위해서는 소비자의 생명 및 신체에 위해를 가하는 것의 최소화, 시술 자에 대한 위생상태 교육 등 무분별한 시술을 제한할 수 있는 제도적
인 장치를 마련하고, 의료법상 의료 행위와 대체의학을 구분할 수 있 는 명확한 법적 기준을 만들어 대체의학을 합법적으로 활용할 수 있 는 제도적인 장치와 이를 뒷받침 할 수 있도록 체계적인 학술적 접근 이 필요하고, 증거에 기초한 과학적인 임상적 결과를 도출하는 다양 한 연구가 필요하다.

또한 본 연구에서 연구대상자인 피부관리사들은 전체 재교육 받은 경험자가 대부분으로, 대체의학과 관련된 범주의 모든 프로그램을 재교육한 결과가 아니기 때문에 모든 피부관리사들의 결과로 일반화 하거나, 모든 대체의학 범주의 재교육 결과로 일반화하기엔 한계점 이 있다. 따라서 대체의학 교육을 받은 피부관리사들을 대상으로 추 가적인 연구가 필요하다고 사료된다.

This work is part of the Won Bum Shin's Ph.D. thesis at the Konkuk University, Seoul, Korea.

\section{Author's contribution}

WBS designed, performed experiments, analyzed data, and wrote the manuscript. YSK supervised the project. All figures are created by the author and the co-authors. All authors read and approved the final manuscript.

\section{Author details}

Won-Burn Shin (Graduate student), Department of Cosmetics Engineering, Konkuk University, 120 Neungdong-ro, Gwangjin-gu, Seoul 05029, Korea; YoungSam Kim (Professor), Department of Image Industry, Graduate School of Engineering, Konkuk University, 120 Neungdong-ro Gwangjin-gu, Seoul 05029, Korea.

\section{References}

Choi DH, Kim CH, Shin HC, Park YW, Sung EJ, Lee KH. Patterns of complementary and alternative medicine therapies in patients with chronic fatigue or pain. Korean Journal of Family Medicine, 30: 182-189, 2009.

Daykin AR, Richardson B. Physiotherapists' pain beliefs and their influence on the management of patients with chronic low back pain. Spine, 29: 783-795, 2004.

Han B, Kim W, Hong S. The study on the effect of relaxation of stress E.D.T applies. Journal of the Korean Society of Radiology, 6: 515-520, 2012.

Jeon YA, Woo N. A meta-analysis of obesity management 
effects of aromatherapy use. Asian Journal of Beauty and Cosmetology, 12: 275-281, 2014.

Jeong ES, Choi SJ. A study on the re-training of alternative therapy. Journal of Beauty Industry, 3:79-91, 2008.

Jung YS, Huh EO, Song DH, Whang WK. The effect of reeducation of primary clinics and skin care shop esthetician on the job satisfaction. Asian journal of beauty \& cosmetology, 12: 33-40, 2014.

Kang YS, Jang GS. A study on the understanding and satisfaction of aroma therapy in beauty-related departments students. Journal of the Korean Society of Beauty Cultural Arts, 1: 76-84, 2012.

Kim EY. A study on the present status for alternative therapy and on future outlook for esthetic field. Journal of the Korean Society for Beauty Health, 2: 185-195, 2009.

Kim MJ. Affecting factors for job stress and client service of estheticians in the medical beauty industry. Asian Journal of Beauty and Cosmetology, 17: 157-168, 2019.

Kim TY, Lee SN. The mediating effect of job satisfaction on the relationship between internal marketing and the customer orientation of employees in the beauty service industry. Asian Journal of Beauty and Cosmetology, 16: 555-567, 2018.
Kim YS. A theoretical analysis on the foot reflexology emerging as an alternative medicine. New Medical Journal, 44: 87-94, 2001.

Lee TY, Kim N, Maeng W. Changing definitions of complementary and alternative medicine and related research analysis in Korea. Korean Journal of Oriental Medicine, 16: 43-55, 2010.

Min IS, Park JH, Lim JH, Park EJ. How to uniform satisfaction affected by uniform recognition in the beauty services workers. Asian Journal of Beauty and Cosmetology, 11: 289-296, 2013.

Park HS, Hyun KS. Factors influencing on use of complementary $\cdot$ aternative therapy on chronic patients. Journal of East-West Nursing Research, 17: 1-8, 2011.

Rhee $\mathrm{NH}$. Impact of the reeducation satisfaction of skincare specialists on multi-dimensional organizational commitment. Journal of the Korean Society of Beauty and Art, 17: 59-70, 2016.

Yoo HJ, Roh EY, Lee C, Han OS. The psychosocial characteristics influencing the selection of complementary medicine. Journal of the Korean Neuropsychiatric Association, 38: 738-746, 1999. 


\section{국문초록}

\section{대체의학에 대한 피부관리사의 인식도가 경영성과에 미치는 영향}

신원범 ${ }^{1}$, 김영삼 ${ }^{2 *}$

${ }^{1}$ 건국대학교 화장품공학과, 서울, 한국

${ }^{2}$ 건국대학교 산업대학원 이미지산업학과, 서울, 한국

목적: 본 연구는 고객의 Needs를 충족시킬 목적으로 피부관리사 재교육 프로그램 참여자를 대상으로 대체의학에 대한 인식도가 경 영성과에 미치는 영향을 조사하여 분석한 양적 연구이다. 방법: 연구 대상은 현재 피부 관리 업무를 하는 전국의 남녀 596 명을 대상 으로서 기간은 2020년 2월1일부터 2월 20일까지 온라인 설문을 통하여 진행 하였다. 수집된 자료는 SPSS (Statistical Package for the Social Science) WIN 25.0 통계 프로그램을 이용하여 분석하였다. 분석기법으로는 대체의학 인지도 및 인식, 대체의학 요법에 대한 경험 및 태도, 신뢰도, 대체의학의 교육 실태 및 인식, 대체의학의 유용성에 대한 인식을 검증 하기 위해 One-way ANOVA (일 원변량분석)과 t-test (검증), $\chi^{2}$ (Chi-square) 검증, 그리고 빈도분석을 실시하였다. 또한 대체의학 이용 만족도와 유용성에 영향 을 미치는 요인을 알아보기 위해 Multiple Regression(다중회귀분석)을 실시하였다. 결과: 대체의학 학습 후 고객 적용 시 $32.2 \%$ 의 피부관리사가 샵의 수익에 50\%이상 도움이 되었다고 조사되었고, 20-30\% 고객 수가 증가되었다는 응답이 $27.9 \%$ 로 가장 많았다. 대체의학에 대한 태도가 긍정적일수록, 신뢰도가 높을수록, 그리고 대체의학 정규 과목 개설이 필요하다고 인식할수록 대체의학 이 용 만족도가 높음을 알 수 있다. 결론: 따라서 대체의학에 대한 재교육과 현실적인 제도가 필요한 것을 알 수 있다.

핵심어: 피부관리사, 대체의학, 인식도, 재교육, 경영성과

\section{참고문헌}

강영숙, 장경선. 미용관련학과 대학생의 아로마테라피에 대한 인식도와 만족도에 관한 연구. 대한미용문화예술학회지, 1 :

76-84, 2012.

김문주. 병원 내 피부미용사의 직무 스트레스와 대 고객 서비스 관련 요인. 아시안뷰티화장품학술지, 17: 157-168, 2019.

김은영. 대체요법의 현황과 피부미용분야 향후 전망에 관한 연구. 한국미용건강학회지, $2: 185-195,2009$.

김예성. 대체의학으로서의 발 반사요법. 최신의학, $44: 87-94,2001$.

김태열, 이성내. 뷰티서비스업 구성원의 내부마케팅과 고객지향성의 관계에서 직무만족의 매개효과. 아시안뷰티화장품학 술지, 16: 555-567, 2018.

민인숙, 박재홍, 임지현, 박은준. 미용서비스 종사자의 유니폼 인식이 유니폼 개선사항에 미치는 영향. 아시안뷰티화장품

학술지, 11: 289-296, 2013.

박현신, 현경선. 만성질환자의 보완대체요법 이용에 영향을 미치는 요인. 동서간호학연구지, 17: 1-8, 2011. 유희정, 노은여, 이철, 한오수. 대체의학 선택에 영향을 미치는 일반인들의 심리사회적 특성. 신경정신의학, 38: 738-

746, 1999.

이난희. 피부미용사의 재교육 만족이 다차원적 조직몰입에 미치는 영향. 한국인체미용예술학회지, 17: 59-70, 2016. 이태형, 김남일, 맹웅재. 보완대체의학의 정의 변화와 국내 관련 연구 분석. 한국한의학연구원논문집, $16: 43-55,2010$. 전연아, 우나리야. 아로마테라피를 이용한 비만관리효과의 메타분석. 아시안뷰티화장품학술지, 12: 275-281, 2014. 정연선, 허은옥, 송다해 황완균. 재교육이 1 차 의료기관과 개인피부관리실 피부미용사의 직무만족도에 미치는 영향. 아시 안뷰티화장품학술지, $12: 33-40,2014$.

정은숙, 최선자. 대체요법 재교육에 관한 연구. 뷰티산업연구, 3: 79-91. 2008. 
최다해, 김철환, 신호철, 박용우, 성은주, 이계화. 만성 피로 및 만성 통증 환자에서의 보완 대체 요법의 이용 양상. Korean Journal of Family Medicine, 30: 182-189, 2009.

한병성, 김원준, 홍성균. E.D.T 적용이 스트레스 완화에 미치는 효과 연구. 한국방사선학회 논문지, 6: 515-520, 2012. 


\section{中文摘要}

\section{美容师对替代医学的认识对经营绩效的影响}

愼元範 1, 金永三 二 $^{2 *}$

建国大学化妆品工学科, 首尔, 韩国

2建国大学产业大学院影像产业学科, 首尔, 韩国

目的: 这是一项定量研究, 其中使用皮肤护理再培训计划中的参与者来调查和分析对替代医学的认知对管理绩效 的影响，以便满足客户需求。方法：从2020年2月1日至2月20日，对全国596名目前从事皮肤护理工作的男女进 行了在线调查。使用SPSS WIN 25.0对收集的数据进行了分析。进行了单向方差分析, $t$ 检验, $x^{2}$ 检验和频率分 析, 以验证对替代医学的认识和认知, 替代医学治疗的经验, 态度和可靠性, 替代医学培训的状态和认知以及 替代有效性的认知药物。此外, 进行了多元回归分析, 以找出影响使用替代医学的满意度及其有效性的因素。 结果: 当被问及美容师向客户提供替代医学的效果如何时, 接受替代医学培训后, 有 $32.2 \%$ 的受访者说这为利润 增长贡献了 $50 \%$, 而 $27.9 \%$ 的受访者说它为利润增长做出了贡献客户数量增加了 $20 \%-30 \%$ 。结果表明, 态度越 积极, 对替代医学的可靠性越高, 对开放替代医学的感知需求越强, 用户的满意度就越高。结论: 因此, 似乎需 要对替代医学进行再培训计划以及系统的改变。

关键词: 皮肤护理专业人员, 替代医学, 意识, 再培训, 管理绩效 